Short Communication

\title{
ORAL AND CRANIOFACIAL CHARACTERISTICS OF UNTREATED ADULT UNILATERAL CLEFT LIP AND PALATE INDIVIDUALS
}

\author{
M. S. Ravi \\ Professor, Dept. of Orthodontics, A. B. Shetty M emorial Institute of Dental Sciences, M angalore. India - 575018 \\ Correspondence \\ M. S. Ravi \\ Professor, Dept. of Orthodontics, A. B. Shetty Memorial Institute of Dental Sciences, M angalore. India - 575018 \\ Mobile : +9198452 21386, Fax: +91824 2204776, E-mail : drmsravi@gmail.com
}

\begin{abstract}
:
Introduction : Cleft lip and palate anomaly being the common congenital defect having significant effects on the facial morphology, function and growth and development of the individual, requires a detailed study of the Dental and craniofacial characteristics.

Design and setting: The study is conducted in a hospital set up and the subjects were selected at random as per the inclusion criterion. Objectiveof study was to evaluate the craniofacial and Dental morphology in untreated unilateral cleft lip and palate (UCLP) individuals.

Materials and Methods : A total of 64 individuals in the age group of 15-28 yrs were selected and grouped in to two groups; Cleft group consisting of 13 males and 19 females having untreated UCLP and another group of 16 male and 16 female non cleft individuals. Study cast, lateral cephalogram and frontal cephalogram analysis were carried out. The obtained data were analyzed using ANOVA to compare the values between the groups.
\end{abstract}

Result : Significant differences in cranio- facial characteristics were noted between the cleft and non cleft individuals. These differences were more pronounced in sagittal plane and less in transverse plane.

Conclusion: Significant differences exist in the cranio- facial morphology between the untreated UCLP individuals and non cleft individuals.

Keywords: lateral Cephalogram, Frontal Cephalogram, Cleft, Cranio facial morphology

\section{Introduction :}

Cleft lip and palate anomaly is one of the most frequently encountered congenital malformations caused due to morphologic changes, altered growth factors, and absolute tissue deficiency in the hard palate and abnormal tissues in the M axillo-palatal region. ${ }^{1}$

The defects usually associated with cleft lip and palate patients are those of growth in all three planesi.e. vertical, sagittal and transverse plane. The most striking feature in a cleft patient is the sagittal deficiency of the mid face

Access this article online Quick Response Code

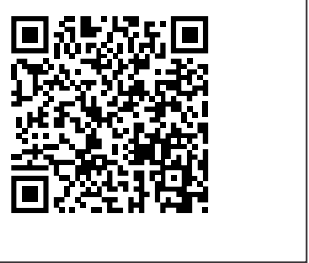
leading to a concave facial profile. The mid facial deficiency is progressive and can be observed in early ages ${ }^{2}$. The majormorphologic characteristic in complete cleft lip and palate individuals is the result of altered response of skeletal elements to muscular deformation tendencies. Studies comparing the craniofacial features among cleft individuals have demonstrated significant differences in various parameters when compared with that of the non cleft individuals. ${ }^{3,4}$

The Comprehensive management of Cleft lip and palate cases requires a team effort, consisting of various specialists. The multitudes of problems associated with the unfortunate individuals include Growth defects, Dental arch abnormalities $s^{6,7}$, and morphological defects $s^{8,9}$ and also the esthetic and psychological trauma that the individual undergoes. Orthodontic treatment involves alveolar molding, arch expansions, growth modifications and arch alignments at different stages of management. The appropriate treatment regimen has to be selected based on the individual cases keeping in mind the patient's age and the growth status. ${ }^{10}$ 


\section{Aims and objectives:}

The study was carried out to evaluate the facial morphology of untreated adult cleft lip and palate individuals and to compare them with that of non cleft individuals. The data obtained from the facial morphology of untreated adult cleft lip and palate individuals can be used as an aid in diagnosis and treatment planning and also as a standard guide for surgical and / or orthodontic intervention for cleft individuals.

\section{Materials and Methods:}

32 Untreated Adult Unilateral Cleft lip and palate (UCLP) individuals and 32 Non Cleft individualsmatched by age and gender were selected for the study as per the following inclusion criteria.

Group I: Control Group (15-28yrs); 16 males and 16females

- Adult Subjects with pleasing profile, Class I skeletal relationship, with near normal Occlusion

- No prior Ortho. / Surgical treatments

Group II: Untreated adult Cleft (15-28 yrs); 13 males and 19 females

- Unilateral Cleft lip and palate individuals with No history of prior treatments what so ever for the defect

Upper and lower study casts were prepared after obtaining the informed consent. Lateral \& Frontal cephalograms were made under the standard conditions using PlanmecaProline 2002 machine (Planmeca, Finland) and were traced on to an acetate paper using $0.5 \mathrm{~mm}$ pencil andwere analyzed for the various craniofacial characteristics. A total of 7 parameters in lateral cephalogram [Fig.1] and 11 parameters in frontal cephalogram [Fig.2] were measured and analyzed. [Table1]

The Data obtained were subjected to ANOVA test to determine the statistical significance between the groups.

\section{Result:}

\section{Study Cast analysis:}

While the Inter canine width and Palatal height were significantly different in males, the palatal height and palatal distance were significantly different in females. [Table2]

The following observations were also made in cases of cleft lip and palate individuals.

- Missing Teeth- Lateral incisor (14);Central incisor (12) and Canine (4)

- Impacted Teeth- Canines (14); Lateral incisor(12) and Central incisor(3)

- Retained Deciduous Teeth- Canines (14) and Lateral incisor (8)

- Rotated Incisors- All the cases

- Peg Lateral -2

- Supernumerary Teeth (M esiodens) - 2

- Transpositions of canine and premolar - 2

- Generalized Spacing - 6

\section{Lateral Cephalometric Analysis:}

The craniofacialparameters, Go-Gn, Co-Go, Co-Gn, Co-Go$\mathrm{Me}$, facial height ratio, and SNB values showed statistically high to very high significant differences between the groups.Only the anterior cranial base measurement in female subjects was not significantly different. [Table3 \& 4 ]

\section{Frontal Cephalometric Analysis:}

The frontal analysis and comparison between the groups showed that only the lo1-lo1-/Lo-Lo measurement was significantly different between the groups, whereas the other parameters were statistically not significant between the groups. [Table $5 \& 6$ ]

\section{Discussion:}

Cleft lip and palate anomaly is one of the most frequently encountered congenital malformations. The defect usually associated with cleft lip and palate patients are those of growth in all three planes i.e. Vertical, Sagittal and Transverse planes. These patients are generally characterized as possessing abnormalities of the dental arch form, malocclusion, facial deformity and masticatory function. ${ }^{1}$ In terms of gonial angle width, the results obtained in the present study are in contradiction with the study done by Dixon ${ }^{11}$ in 1966, Ishiguro ${ }^{12}$ et al in 1976, Ross 
and Johnston ${ }^{13}$ in 1967. Dahl ${ }^{8}$, in a study reported no significant differences in arch dimensions between cleft and non cleft groups.

The present study indicated that the cleft individuals had smaller anterior Cranial base length (SN); Short M andibular body length (Go-Gn); Short Mandibular overall length (CoGn); Short Ramus height (Co-Go); Obtuse Gonial angle, steep Mandibular plane; Reduced posterior facial height, increased anterior facial height, Mandible rotating downwards and backwards and M idface deficiency (SNA) when compared to non cleft individuals.

Horswell and Lavent (1988) ${ }^{14}$ evaluated craniofacial growth in UCLP patients and reported reduced maxillary arch length in cleft individuals. Blanco, Brece et al., (1989) ${ }^{15}$ also showed significant reduction in all the arch dimensions in cleft palate patients. Omar Gabriel, Camargo et al $(1992)^{16}$ in their study on the influence of cleft on maxillary arch morphology, concluded that maxillary arch is distorted in the presence of cleft. Similar results were also

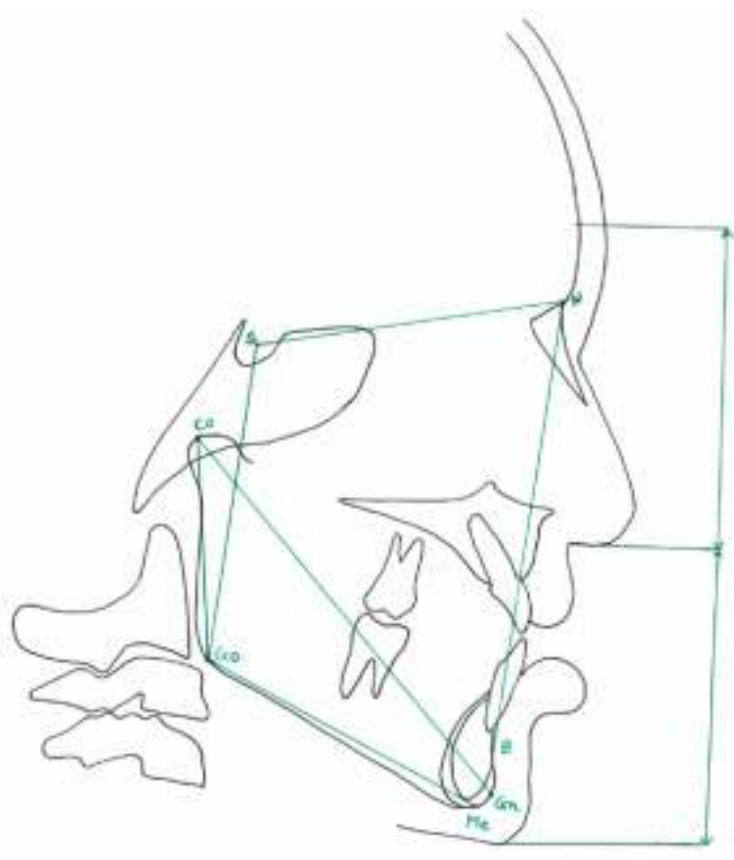

Fig.1: Lateral Cephalometric measurements reported by Heidbuchel, Jagtmanet al ${ }^{17}$ in 1997.

The data obtained from the present study may be used as an aid in diagnosis and treatment planning and also as a standard guide for Surgical and/ or Orthodontic interventions for Cleft individuals.

\section{Conclusion:}

Significant variations are observed in Dental and Craniofacial form in Untreated Adult UCLPindividuals when compared to non cleft individuals. Facial characteristics were significantly different in sagittal plane when compared to that in the transverse plane. Significant differences were also observed in the dental characteristics between the untreated adult UCLP individuals and the non cleft individuals.

Further studies need to be carried out on different types of oro-facial clefts taking into account age and ethnicity of the individuals. Such investigations need to be conducted on a longitudinal basis to study the effects of cleft on the growth and development of the individual.

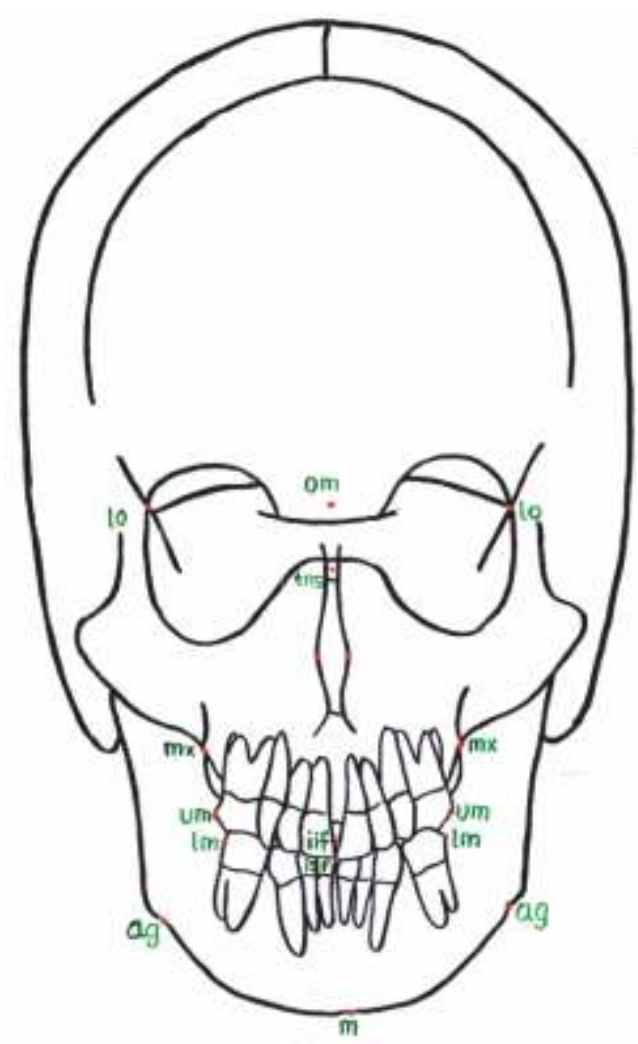

Fig.2: Frontal Cephalometric measurements 
Table 1: Parameters used in the study

\begin{tabular}{|l|l|}
\hline Sr. No & Study Cast analysis \\
\hline 1 & Inter canine width \\
\hline 2 & Inter Pre molar width \\
\hline 3 & Palatal Height \\
\hline 4 & Palatal distance \\
\hline Lateral Cephalometric analysis \\
\hline 1 & S-N \\
\hline 2 & Go-Gn \\
\hline 3 & Co-Go \\
\hline 4 & Co-Gn \\
\hline 5 & Co-Go-Me \\
\hline 6 & Facial ht. ratio \\
\hline 7 & SNB \\
\hline Frontal Cephalometric analysis \\
\hline 1 & Ins-Ins/lo-lo \\
\hline 2 & mx-mx/lo-lo \\
\hline 3 & um-um/lo-lo \\
\hline 4 & um-um/mx-mx \\
\hline 5 & Im-Im/lo-lo \\
\hline 6 & um-um/lm-Im \\
\hline 7 & ag-ag/lo-lo \\
\hline 8 & mx-mx/ag-ag \\
\hline 9 & Io-om-isf \\
\hline 10 & Io-om-iif \\
\hline 11 & Io-om-m \\
\hline & \multicolumn{2}{|l|}{} \\
\hline
\end{tabular}

Table 2: Model Analysis - UCLP Vs Contro

\begin{tabular}{|c|c|c|c|c|c|}
\hline Gender & Parameters & Group & Mean & Standard & $\mathbf{T}$ \\
\hline & & & Deviation & & \\
\hline \multirow{8}{*}{ Male } & \multirow{2}{*}{ Inter Canine Width } & Cleft & 31.9167 & 7.2921 & 2.0580 \\
\hline & & Control & 35.8000 & 0.7746 & $P=0.05 \mathrm{sig}$ \\
\hline & \multirow{2}{*}{ Inter Premolar Width } & Cleft & 36.8750 & 5.2138 & 0.2260 \\
\hline & & Control & 37.2000 & 2.0071 & $\mathrm{P}=0.823 \mathrm{NS}$ \\
\hline & \multirow[t]{2}{*}{ Palatal Height } & Cleft & 17.3846 & 3.0149 & 2.3390 \\
\hline & & Control & 14.6000 & 3.2470 & $P=027 \mathrm{sig}$ \\
\hline & \multirow[t]{2}{*}{ Palatal Dist } & Cleft & 25.6667 & 6.5273 & 0.5900 \\
\hline & & Control & 26.8000 & 3.2338 & $P=561 N S$ \\
\hline \multirow[t]{8}{*}{ Female } & \multirow[t]{2}{*}{ Inter Canine Width } & Cleft & 31.4444 & 6.3465 & 0.0720 \\
\hline & & Control & 31.6000 & 4.2224 & $P=943 N S$ \\
\hline & \multirow[t]{2}{*}{ Inter Premolar Width } & Cleft & 35.7143 & 4.4795 & 1.2660 \\
\hline & & Control & 37.2000 & 0.7746 & $P=0.216 \mathrm{NS}$ \\
\hline & \multirow[t]{2}{*}{ Palatal Height } & Cleft & 19.0000 & 3.2404 & 2.1830 \\
\hline & & Control & 16.6000 & 1.6818 & $\mathrm{P}=.043 \mathrm{sig}$ \\
\hline & \multirow[t]{2}{*}{ Palatal Dist } & Cleft & 23.8000 & 2.3875 & 2.2390 \\
\hline & & Control & 27.6000 & 3.5010 & $P=038$ sig \\
\hline
\end{tabular}

Table 3: Lateral cephalometric analysis-Cleft vs Control (Male)

\begin{tabular}{|l|l|c|c|r|}
\hline Sl. No & Measurements & Non Cleft & Cleft & T \\
\hline 1 & S-N & $78 \pm 4$ & $74.2 \pm 4.2$ & 3.50 \\
& & & & $\begin{array}{r}P=0.0009 \\
\text { VHS }\end{array}$ \\
\hline 2 & Go-Gn & $81.9 \pm 5.1$ & $75.3 \pm 6.1$ & 4.404 \\
& & & & $\begin{array}{r}P \\
<.0001 \\
\text { VHS }\end{array}$ \\
\hline 3 & Co-Go & $63.6 \pm 4.5$ & $55.7 \pm 6.1$ & 5.496 \\
& & & & $\begin{array}{r}P<0.0001 \\
\text { VHS }\end{array}$ \\
\hline 4 & Co-Gn & $130.1 \pm 6.7$ & $122.6 \pm 3.5$ & 5.485 \\
& & & & $P<0.0001$ \\
& & & & VHS \\
\hline 5 & Co-Go-Me & $124 \pm 4.3$ & $132.0 \pm 4.5$ & 6.61 \\
& & & & $P<0.0001$ \\
& & & & VHS \\
\hline 6 & Facialht. Ratio & $65.5 \pm 2.5$ & $67.2 \pm 3.5$ & 2.08 \\
& & & & $P \varangle 0.042$ \\
& & & & SIG \\
\hline 7 & SNB & $81 \pm 2$ & $76.5 \pm 3.5$ & 5.823 \\
& & & & $P<0.0001$ \\
& & & & VHS \\
\hline
\end{tabular}

Table 4 : Lateral cephalometric analysis-Cleft Vs Control (Female)

\begin{tabular}{|l|l|r|r|r|}
\hline Sl. No & Measurements & Non Cleft & Cleft & T \\
\hline 1 & S-N & $72.5 \pm 3.2$ & $70.6 \pm 2.8$ & 2.007 \\
& & & & $\begin{array}{r}P=0.0516 \\
\text { NS }\end{array}$ \\
\hline 2 & Go-Gn & $73.6 \pm 2.5$ & $66.8 \pm 3.4$ & 7.477 \\
& & & & $\begin{array}{r}P<0.0001 \\
\text { VHS }\end{array}$ \\
\hline 3 & Co-Go & $58.5 \pm 3.6$ & $50.4 \pm 3.8$ & 7.047 \\
& & & & $\begin{array}{r}P<0.0001 \\
\text { VHS }\end{array}$ \\
\hline 4 & Co-Gn & $126.4 \pm 4.6$ & $120.2 \pm 2.6$ & 5.127 \\
& & & & $\begin{array}{r}P<0.0001 \\
\text { VHS }\end{array}$ \\
\hline 5 & & & & 4.162 \\
& & $125 \pm 3.4$ & $130.8 \pm 5.6$ & $P<0.0002$ \\
& & & & HS \\
\hline 6 & Facial ht.Ratio & $66.2 \pm 2$ & $68.4 \pm 2.5$ & 3.169 \\
& & & & $P<0.0029$ \\
& & & & HS \\
\hline 7 & SNB & $80.7 \pm 4.2$ & $76.3 \pm 3.5$ & 3.602 \\
& & & & $P<0.0009$ \\
& & & & VHS \\
\hline
\end{tabular}


Table5: Frontal Cephalometric analysis-Cleft Vs Control (Male)

\begin{tabular}{|c|c|c|c|c|c|}
\hline M easurements & Groups & Mean & SD & 't' value & 'p' value \\
\hline \multirow[t]{2}{*}{ Ins-Ins/lo-lo } & Cleft & 0.0603 & 0.0074 & \multirow[t]{2}{*}{7.2130} & \multirow[t]{2}{*}{0.001 vhs } \\
\hline & Control & 0.0430 & 0.0017 & & \\
\hline \multirow[t]{2}{*}{$m x-m x / 10-10$} & Cleft & 0.7263 & 0.0336 & \multirow[t]{2}{*}{0.4210} & \multirow[t]{2}{*}{$0.679 \mathrm{~ns}$} \\
\hline & Control & 0.7191 & 0.0429 & & \\
\hline \multirow[t]{2}{*}{ um-um/lo-lo } & cleft & 0.7400 & 0.0383 & \multirow[t]{2}{*}{1.4330} & \multirow[t]{2}{*}{$0.17 \mathrm{~ns}$} \\
\hline & Control & 0.7122 & 0.0480 & & \\
\hline \multirow[t]{2}{*}{$u m-u m / m x-m x$} & Cleft & 0.9761 & 0.1236 & \multirow[t]{2}{*}{0.3710} & \multirow[t]{2}{*}{$0.175 \mathrm{~ns}$} \\
\hline & Control & 0.9928 & 0.0699 & & \\
\hline \multirow[t]{2}{*}{ Im-Im/lo-Io } & cleft & 0.7367 & 0.0490 & \multirow[t]{2}{*}{1.7720} & \multirow[t]{2}{*}{$0.093 \mathrm{~ns}$} \\
\hline & Control & 0.7771 & 0.0530 & & \\
\hline \multirow[t]{2}{*}{ um-um/Im-Im } & Cleft & 1.0078 & 0.0467 & \multirow[t]{2}{*}{3.1560} & \multirow[t]{2}{*}{$0.005 \mathrm{hs}$} \\
\hline & Control & 0.9196 & 0.0750 & & \\
\hline \multirow[t]{2}{*}{ ag-ag/lo-lo } & cleft & 0.9349 & 0.0465 & \multirow[t]{2}{*}{0.3940} & \multirow[t]{2}{*}{$0.698 \mathrm{~ns}$} \\
\hline & Control & 0.9434 & 0.0497 & & \\
\hline \multirow[t]{2}{*}{$m x-m x / a g-a g$} & Cleft & 0.7785 & 0.0317 & \multirow[t]{2}{*}{0.8580} & \multirow[t]{2}{*}{$0.402 \mathrm{~ns}$} \\
\hline & Control & 0.7633 & 0.0462 & & \\
\hline \multirow[t]{2}{*}{ lo-om-isf } & Cleft & $94.00 \stackrel{0}{0}$ & 5.2705 & \multirow[t]{2}{*}{1.5560} & \multirow[t]{2}{*}{$0.146 \mathrm{~ns}$} \\
\hline & Control & $96.80^{\circ}$ & 2.1499 & & \\
\hline \multirow[t]{2}{*}{ lo-om-iif } & Cleft & $94.80^{\circ}$ & 3.7653 & \multirow[t]{2}{*}{1.4590} & \multirow[t]{2}{*}{$0.162 \mathrm{~ns}$} \\
\hline & Control & $96.80^{\circ}$ & 2.1499 & & \\
\hline \multirow[t]{2}{*}{ lo-om-m } & Cleft & $93.70^{\circ}$ & 5.5588 & \multirow[t]{2}{*}{1.5680} & \multirow[t]{2}{*}{$0.14 \mathrm{~ns}$} \\
\hline & Control & $96.80^{\circ}$ & 2.8597 & & \\
\hline
\end{tabular}

Table 6: Frontal Cephalometric analysis- Cleft Vs Control (Females)

\begin{tabular}{|c|c|c|c|c|c|}
\hline M easurements & Groups & Mean & SD & 't' value & ' $p$ ' value \\
\hline \multirow[t]{2}{*}{$m x-m x / 10-10$} & cleft & 0.7646 & 0.0172 & \multirow[t]{2}{*}{5.3530} & \multirow[t]{2}{*}{$0.001 \mathrm{vhs}$} \\
\hline & control & 0.6789 & 0.0476 & & \\
\hline \multirow[t]{2}{*}{ um-um/mx-mx } & cleft & 0.8515 & 0.0987 & \multirow[t]{2}{*}{3.7260} & \multirow[t]{2}{*}{$0.002 \mathrm{hs}$} \\
\hline & control & 1.0073 & 0.0879 & & \\
\hline \multirow[t]{2}{*}{$1 \mathrm{~m}-\mathrm{Im} / \mathrm{lo}-1 \mathrm{o}$} & cleft & 0.8297 & 0.0804 & \multirow[t]{2}{*}{3.2900} & \multirow[t]{2}{*}{$0.007 \mathrm{Hs}$} \\
\hline & control & 0.7309 & 0.0646 & & \\
\hline \multirow[t]{2}{*}{ um-um/Im-Im } & cleft & 0.8718 & 0.0465 & \multirow[t]{2}{*}{5.6380} & \multirow[t]{2}{*}{$0.001 \mathrm{vhs}$} \\
\hline & control & 0.9626 & 0.0208 & & \\
\hline
\end{tabular}

\section{References:}

1. AIEmran SE, Fatani. E, Hassanain JE. Craniofacial variability in parents of children with cleft lip nadpalate,J.ClinPediatr Dent.1999,23(4);33741

2. Omar Gabriel da silvaFilho, CalvanoF, Antanio GA et al. Craniofacial morphology in children with complete unilateral cleft lip and palate,A comparison of Two surgical protocols.Angle orthod,2001:71(4):274284

3. Trottman CA, PapillonF, Ross RP, et al. A retrospective comparison of frontal facial dimensions in alveolar bone grafted and non grafted unilateral cleft lip and palate patients. Angle Orthod 1997,67(5):389394

4. Nakashima A, Ichinose M. Characteristics of craniofacial structures of parents of children with cleft lip and /or palate. Am J Orthod 1983;84(2):140-46

5. Athansiou AE, Chyong-Yuh-Tseng, Zarinniak et al. Frontal cephalometric study of Dentofacial morphology in children with bilateral cleft lip, alveolus and palate.JCranio-Max-Fac.Surg 1990, 18:49-54

6. Duanne C, Grummons, Martin A et al. A frontal asymmetry analysis.1987, Am J Orthod, Jul,448-465.

7. HamaK. M orphologic study of craniofacial skeleton and profile in cleft lip and palate J Osaka Univ.Dent School.1964;4,41

8. Hermann NV, JensenBL, Dahl E, et al. Craniofacial comparison in 22 month old cleft lip operated children with unilateral complete cleft lip and unilateral in complete cleft lip. Cleft palate Journal.2003; 37(3); 303-17.

9. Omar Gabriel D Silva, Calvano F: Craniofacial morphology in children with complete cleft lip and palate.Angle Orthod.2001,71(4):274-84

10. Bell, William Proffit et al: Surgical correction of Dento facial Deformities. Text book of Oral Surgery, W.B.Saunders 1985

11. Dixon DA: Abnormalities in Teeth and supporting structures in Children with cleft lip and palate. ES Livingstone, London1966:178

12. Ishiguro K, KrogmanWM, Mazaheri M et al. A longitudinal study of morphological patterns via P-A x-ray head films in CLP patients from birth to sixyrs of life. Cleft palate J.1976, 13:104-126.

13. Ross. RB, Johnston M. The effect of early Orthodontictreatment of facial growth in CLP. Cleft palate J.1967, 4:157.

14. Horswell, Levant. Craniofacial growth in UCLP,from 8 to $18 \mathrm{yrs}$.Cleft palate J. 1997;24;114

15. Blanco, Brece. Variation in arch and tooth sizes in upper jaw of cleft palate patients. Odontol chil.1989,37:229-9

16. Omar Gabriel, Camagrog. Influence of Unilateral cleft lip and palate on maxillary dental arch morphology, Angle Orthod.1992, 62:283-290.

17. Heidelbuchel, Jagatman. Maxillary and mandibular dental arch dimensions and occlusions in bilateral cleft lip and palate patients fro3 to 17 yrs of age, Cleft palate cranio-fac. J 1997,34:21-26. 